\title{
Repellency Effects and Chemical Components of Essential Oils Foeniculum Vulgare and Cinnamomum Verum against Aedes Vexans in Iran
}

Mahdi Khoobdel ${ }^{1}$, Mohammad Moradi², Hosien Sobati ${ }^{3}$, Himen Yousefi ${ }^{4}$, Omid Dehghan ${ }^{5}$, Mohammad

\section{Reza Abai ${ }^{6}$}

1. Professor, Health Research Center, Life Style Institute, Baqiyatallah University of Medical Sciences, Tehran, Iran. ORCID ID: 0000-0003-1355-294X

2. MSc. In Medical Entomology and Vector Control, School of Public Health, Tehran University of Medical Sciences, Tehran, Iran. ORCID ID: 0000-0002-2885-0782

3. Assistant Professor, Health Research Center, Life Style Institute, Baqiyatallah University of Medical Sciences, Tehran, Iran. ORCID ID: 0000-0002-2389-7178

4. MSc. In of Medical Entomology and Vector Control, School of Public Health, Tehran University of Medical Sciences, Tehran, Iran. ORCID ID: 0000-0002-6245-4150

5. MSc. In of Medical Entomology and Vector Control, School of Public Health, Tehran University of Medical Sciences, Tehran, Iran. ORCID ID: 0000-0002-2556-991X

6. Instructor, Department of Medical Entomology and Vector Control, School of Public Health, Tehran University of Medical Sciences, Tehran, Iran (Corresponding Author), Tel: +98-21-42933112, Email: abaimr@tums.ac.ir, ORCID ID: 0000-0001-7893-5648

\begin{abstract}
Background and Aim: The presence of different climatic conditions in Iran has resulted in the high richness of medicinal plants. The occurrence of adverse side effects was reported following use of the chemical-based repellents which extensively used for personal protection against nuisance mosquitoes. All the efforts are made for exploring new repellents originated from medicinal plants and could be protected safe and whole night against biting arthropods. This will be an effective action for preventing of risk of arthropod-borne diseases.

Materials and Methods: The fennel seeds and cinnamon bark were chosen due to antibacterial, antioxidant and insecticidal properties. The essential oils were obtained using hydro-distillation using a Clevenger-type apparatus. The chemical components of essential oils were determined by gas chromatography-mass spectrometry. A well-colonized Aedes vexans in insectary was used for repellency assays on the animal model (the white rabbit).

Results: Eighteen and 15 components were identified in the essential oils of fennel and cinnamon and Cadina-1,4-diene and b-Oplopenone were respectively as the main components. The protection time of $50 \%$ essential oils was assessed against lab-bred Aedes vexans, and protection time were estimated 3 and $3.5 \mathrm{~h}$ for $F$. vulgare and 1 and $1.5 \mathrm{~h}$ for $C$. verum, According to a dose-response analysis, the median effective dosage $\left(\mathrm{ED}_{50}\right)$ of essential oils was 13.7 and $84.2 \mu \mathrm{l} / \mathrm{cm}^{2}$ for $F$. vulgare and $C$. verum. Conclusion: The essential oil of $\mathrm{F}$. vulgare could provide acceptable protection against dengue fever vectors on the animal subject. It is recommended to be continued the investigation on human volunteers against other medically important arthropods.
\end{abstract}

Keywords: Foeniculum vulgare, Cinnamomum verum, Essential oil, Repellency, Aedes vexans

Accepted: July 16, 2019

Received: Sep 24, 2019

How to cite the article: Mahdi Khoobdel, Mohammad Moradi, Hosien Sobati, Himen Yousefi, Omid Dehghan, Mohammad Reza Abai. Repellency effects and chemical components of essential oils Foeniculum vulgare and Cinnamomum verum against Aedes vexans in Iran. SJKU 2020;25(1):12-22.

Copyright (C) 2018 the Author (s). Published by Kurdistan University of Medical Sciences. This is an open access article distributed under the terms of the Creative Commons Attribution-Non Commercial License 4.0 (CCBYNC), where it is permissible to download, share, remix, transform, and buildup the work provided it is properly cited. The work cannot be used commercially without permission from the journal 


\section{بررسى اثرات دوركنندىى و تر كيبات شيميايى اسانس كياهان رازيانه و دارجين عليه پشه آندس و كزنس در ايران}

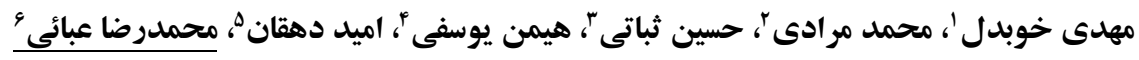

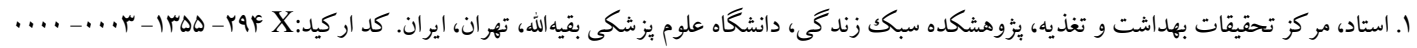

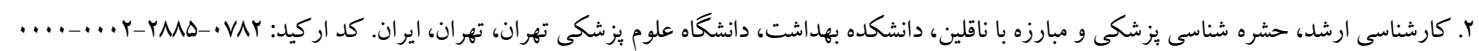

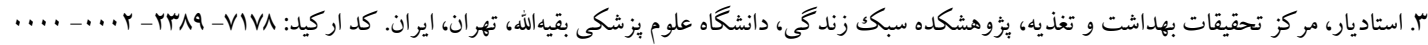

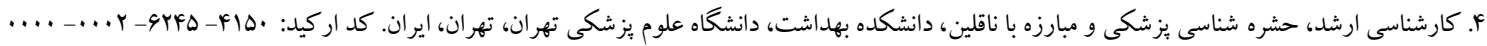

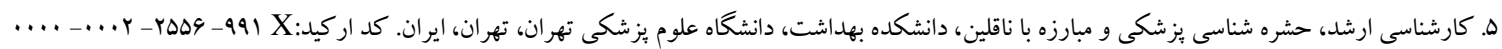

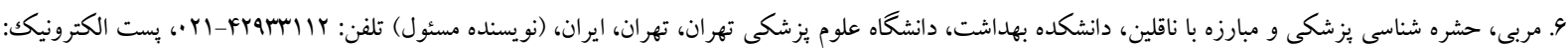

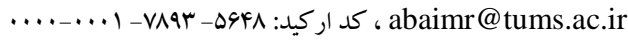

جكيuه

زمينه و هدف: وجود تنوع اقليمى در كشور، زمينه افزايش غناى گُونهاى در گياهان دارويى كشور فراهم كرده است. با توجه به

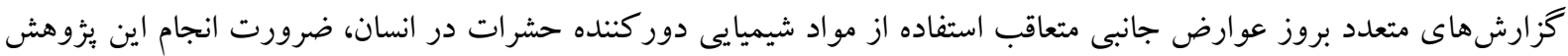

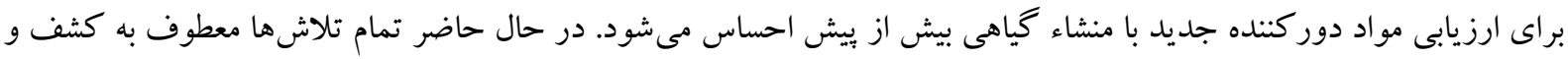

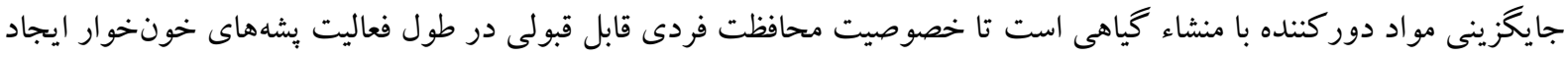

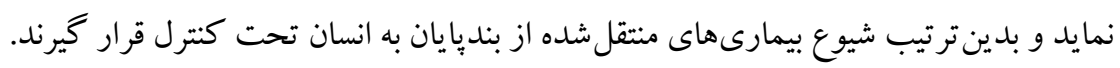

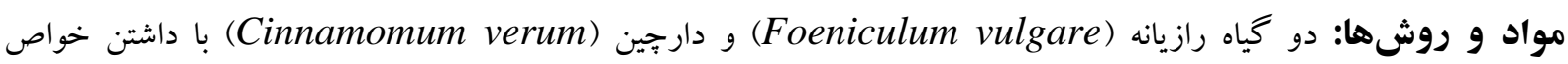

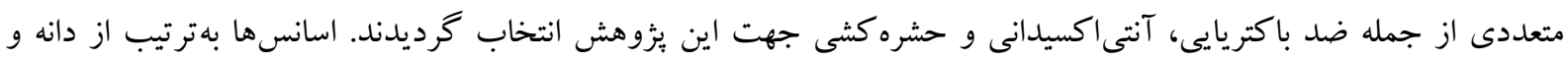

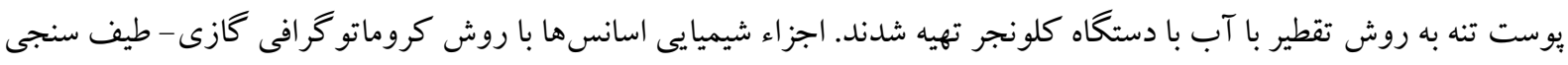
جرمى تعيين شدند. تستهاى زيستسنجى بهمنظور تعيين مدت زمان حفاظتدهى و تعيين دوز مؤثر اسانسها، روى مدل حيوانى

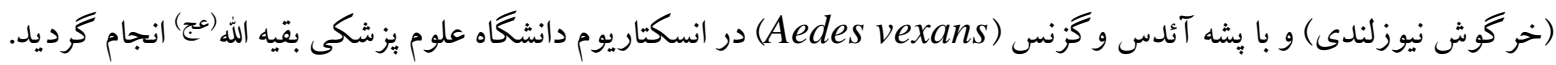

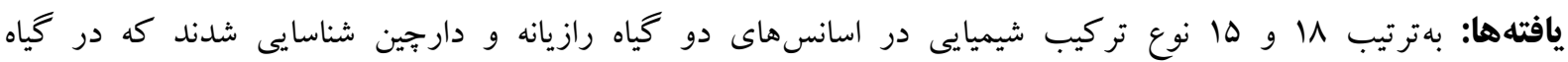

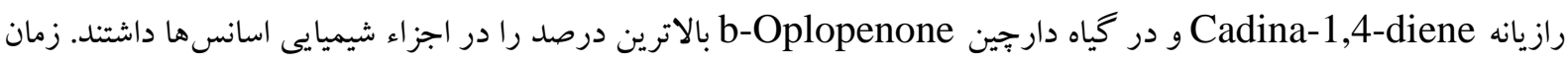

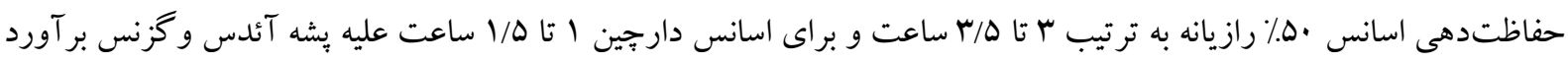

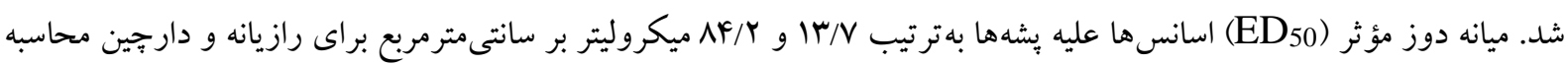

نتيجه كيرى: اين يُزوهش اثرات حفاظتدهى اسانس گياه رازيانه راعليه گزش بشه ناقل تب دانگك در مدل حيوانى در كمترين غلظت نشان داد. انجام اين بزوهش در مدل انسانى توصيه مى شود.

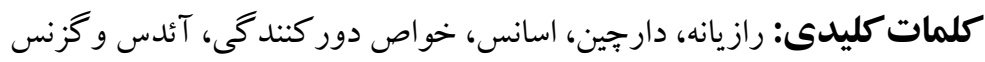

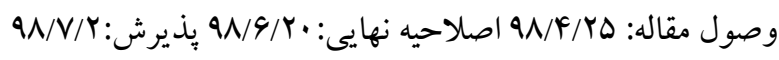


كياه دارويى رازيانه (Foeniculum vulgare) كونهاى علفى و معطر است كه در طبقهبندى در خانواده

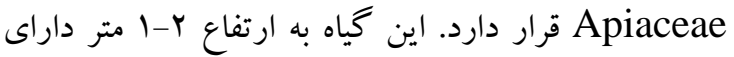

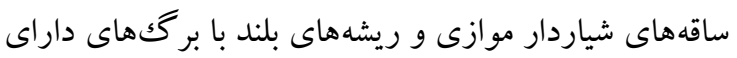

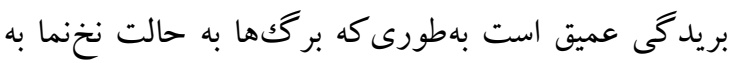
نظر مىرسد. دمبر گها در نزديك ساقه حالت غلاف به بيدا

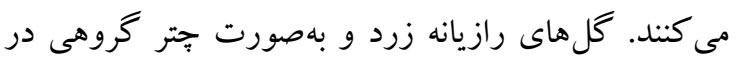

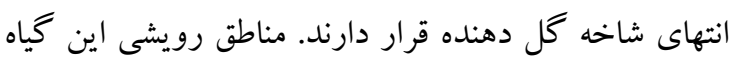

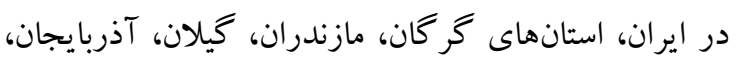

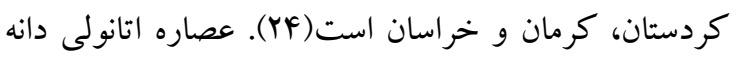
رازيانه از توان ضدميكروبى و ضداكسايشى مناسبى ورسي برخوردار بوده و اسانس دانه آن در غلظتهاى ه/• و 19 /.

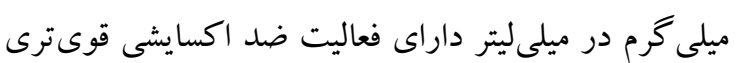

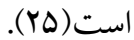
دارجين (Cinnamomum verum) درختى است هميشه سبز از خانواده Lauraceae و از منشاء سيلان و جنوب هند كه ارتفاع آن به V-D متر مىرسد. تمام قسمتهاى اين

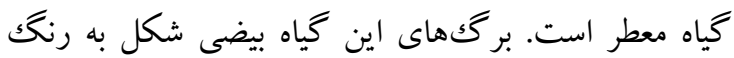
سبز تيره و براق كه بهصورت متقابل بر ساقه مركزى مرتب

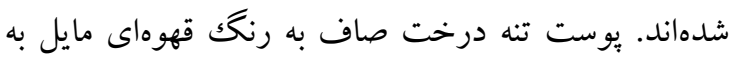
قرمز است. يوست اين درخت حاوى اسانس است(Y)). خو اص ضد انكلى و ضد يشهاى دو گونه از درخت دارجين به نامهاى Ceylanicum و C. verum بررسى شده-

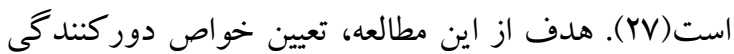
اسانس دو گياه رازيانه و دارجين عليه آئدس و گزنس در مدل حيوانى و در شرايط آزمايشاهى و تعيين اجزاء

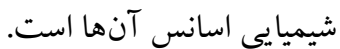

\section{مواد و روشها

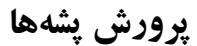

يشهاى مورد نياز جهت تستهاى زيستسنجى از كلنى

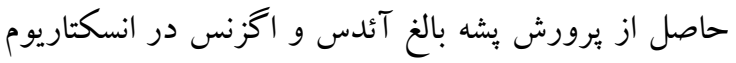

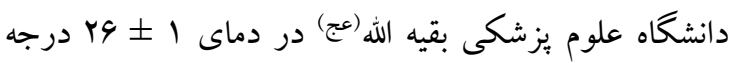

مقدمه

يشههاى كوليسيده (Diptera: Culicidae) به لحاظ نقش آنها در انتقال مالاريا، آربوويروسها و كرمهاى انكل

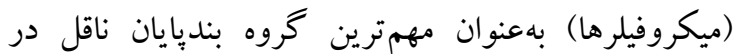
يزشكى و بهداشت مطرح مىباشند. انتقال كرمهاى ديروفيلاريا ايميتيس (Dirofiliaria immitis) و و ديروفيلاريا ريينس (Dirofiliaria repens) بهوسيله برخى گونهاى بشهاى كوليسيده نيز از كشور گزارش شدهاند(ه-1). موارد متعددى از بيمارى ويروسى وست نايل از ديرباز بهعنوان يكك بيمارى منتقل شده از يشهها، از كشور

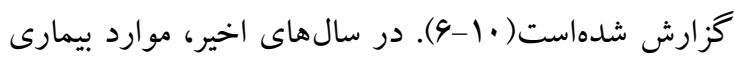

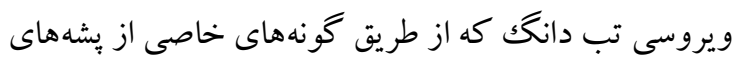
آندس منتقل مى شود در كشورهاى همجوار شرقى ايران به -

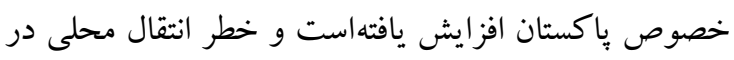

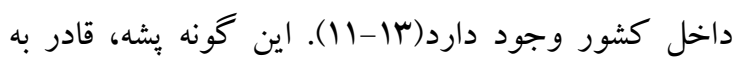
انتقال بيمارىهاى ويروسى تب نيل غربى، آنسفاليتسنت-

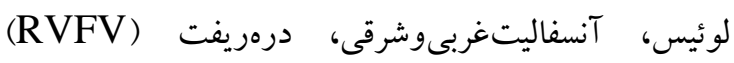

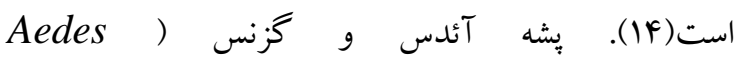
از بشهاى ((Aedimorphus) vexans (Meigen) روز فعال بوده و اوج فعاليت خونخوارى اين يشه بس از غروب آفتاب ملاحظهشده و هم از انسان و هم ساير يستانداران تمايل به خونخوارى دارد(|f). مناسبترين روش براى مقابله با گزش پپشها در فضاى باز، استفاده از مواد دور كننده است. از جنك جهانى دوم، ماده DEET كه يكى از (N, N-diethyl-meta-toluamide) يرمصرف ترين موادى است كه بهعنوان دوركننده مورد استفاده قرار گرفتهاست(ها). اخيراً گزارشهاى از بروز عوارض جانبى اين تركيب شيميايى گزارش شدهاست(19)؛ و در اين راستا محققين ايران و جهان درصدد جايكزينى مواد ديخر بهخصوص مواد دوركنندهاى با منشاء گياهى مىباشند(IV-YI) و در همين راستا، طى مطالعات مختلف

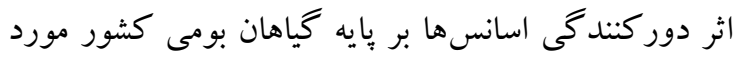

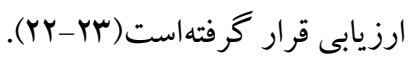




\section{تستهاى دور كنند}

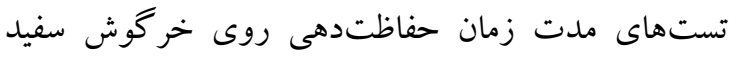

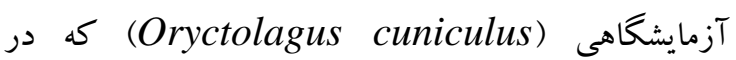

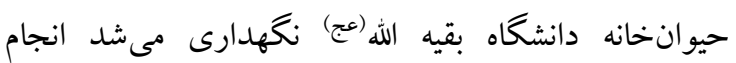

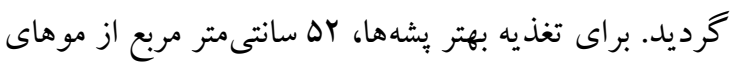
بشت خر گوش تراشيده شد. سه سر خر گوش بهطور مجزا

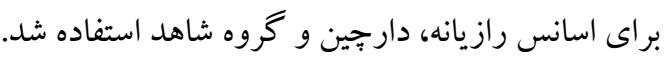
براى انجام تستهاى دور كنندگى از روش استاندارد اعلام

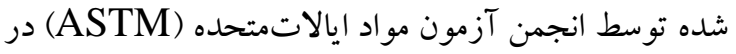
سال .... استفاده شد. غلظت •هـ٪ اسانس ها با اتانول مطلق رقيقسازى شد و جهت تعيين مدت زمان حفاظتدهى به كار

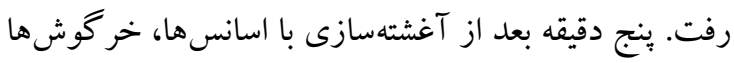
داخل يكك محفظه جوبى محتوى •لها بشه با سن V-ه روز كه rا ساعت قبل از تغذيه از ساكاروز •ا٪ محروم شده بودند انتقال داده شد. شاخص مدت زمان حفاظتدهى در برابر گزش روى يوست آغشته به اسانس در مدت زمان

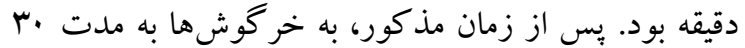
دقيقه استراحت داده مىشد و عمليات مجدد تكرار

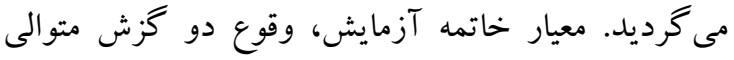

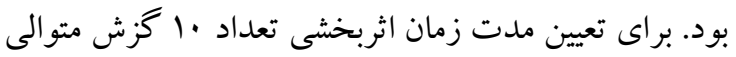
در نظر كرفته شد. دوز مؤثر اسانسها با استفاده از كيت

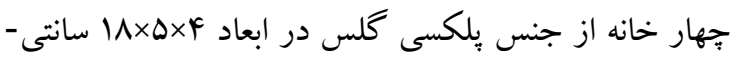

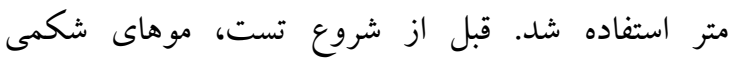

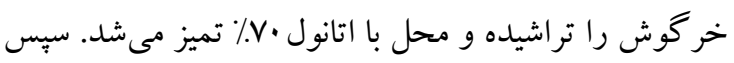
كيت روى شكم خر گوش ثابت مى شد. محل هاى دايرههاى

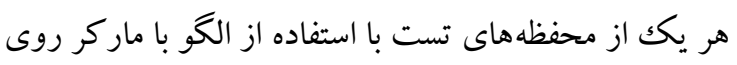

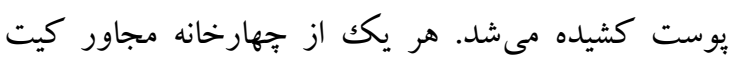
تعداد ه يشه ماده با سن V-ه روزه بهطور تصادفى با لها

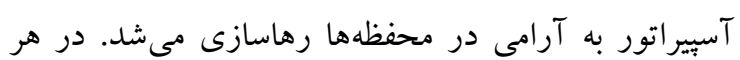

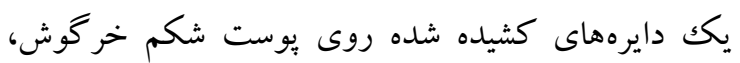

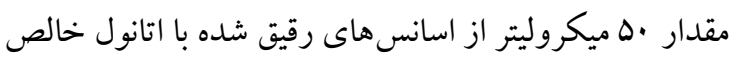

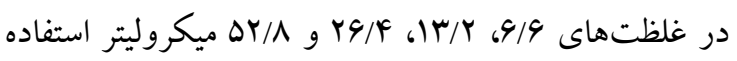

سانتى گراد و رطوبت ه VD د درصد و تحت تناوب تاريكى روشنايى rا:rا ساعت فراهم گُديد. لاروها با غذاى يولكى ماهى بهطور روزانه تغذيه مى شدند و يشههاى بالغ در قفسهاى جوبى با تورى نخهدارى و با محلول ساكاروز

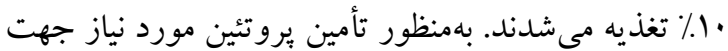
بارورى يشها و افزايش جمعيت از خو كجه هندى بهعنوان

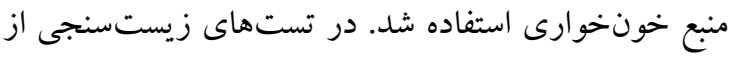

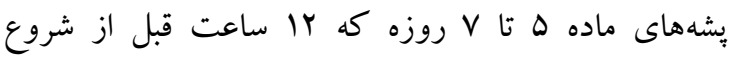
آزمايشهاى از محلول ساكاروز محروم مىشدند، استفاده

تهيه و استخراج اسانسهاى كياهى

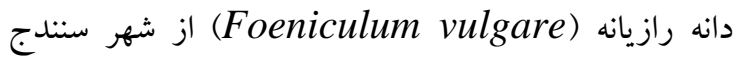
تهيه شد و يوست تنه درخت دارجين ( Cinnamomum از فروشگاه مجاز عطارى در تهران خريدارى شد. (verum اسانس گياهان مورد بررسى با روش تقطير با آب با استفاده از دستگاه كلونجر تهيه شد. اسانسها تا زمان تست در دماى F ادرجه سانتى گر اد نخههارى شدند.

جداسازى تر كيبات اسانسها

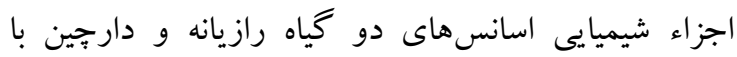

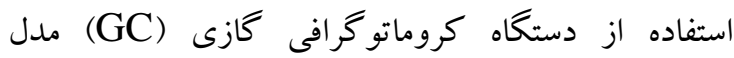
Varian CP-3800 مورد آناليز قرار گرفتند. ستون مورد استفاده (VF-5MS) هاr/· ميلىمتر ضخامت بود. دماى اوليه آون •ه درجه r4. سانتى گراد به مدت ا دقيقه و دماى محفظه تزريق درجه سانتى گراد بوده و از گاز هليوم بهعنوان كاز حامل با لـان سرعت ا ميلىمتر در دقيقه استفاده شد. دستگاه طيفسنج

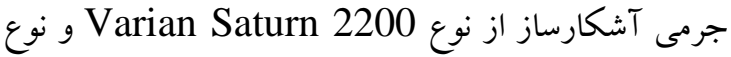
ستون VF-5MS به طول •r متر، هـ/· ميلىمتر قطر و

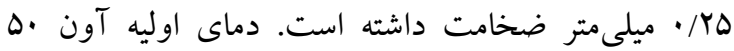
درجه سانتى گراد به مدت ا دقيقه و دماى محفظه تزريق

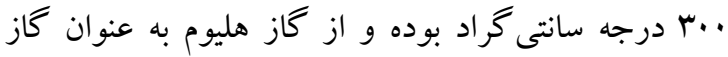

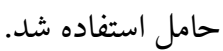


يافتهها

جداسازى تر كيبات اسانسها

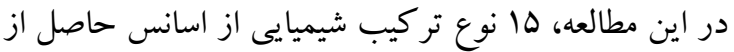
يوست درخت دارجين جداسازى شد كه در بين آنها سه

تركيب b-oplopenone ،

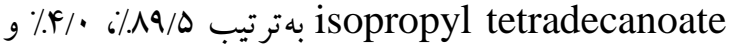

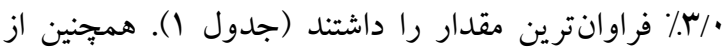
اسانس حاصل از دانه رازيانه تعداد If تركيب شيميايى Cadina-1,4- شناسايى شد كه فراوانترين اجزاء شيميايى Tetracosane و بهترتيب با Y/Y diene

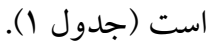

شد. براى هر سه دايره مشخص شده روى يوست شكم خركوش از غلظت مشابه استفاده شد تا از تداخل در آزمايشهاى بيشخيرى شوند. آزمايشهاى تعيين دوز مؤثر

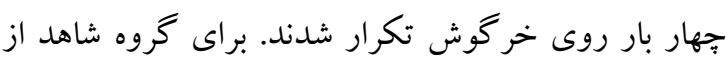
اتانول خالص استفاده شد. در زمان مواجهه، صبر مىشد تا اسانس در محلهاى مشخص شده خشك شود و سِّ كيت جهارخانه محتوى

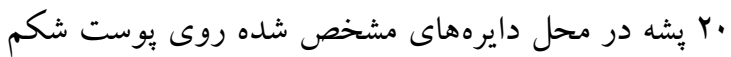
خر گوش قرار داده مىشد. در مدت زمان تماس هـ ده دقيقه،

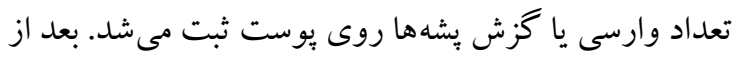
تست، پֶههاى مواجههيافته به داخل كايس منتقل شده و

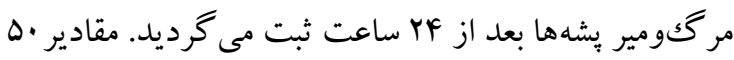

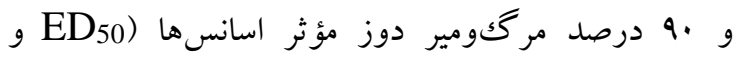

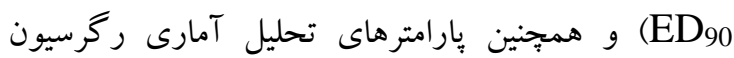

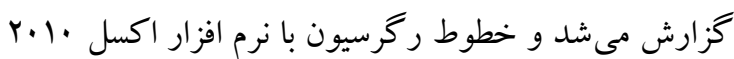

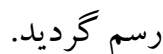

جدول ا. تركيبات شيميايى اسانسهاى دانه رازيانه و يوست دارجين

\begin{tabular}{|c|c|c|c|c|c|}
\hline \multicolumn{3}{|c|}{ اجزاء اسانس يوست درخت دارجين (C. verum) } & \multicolumn{3}{|c|}{ اجزاء اسانس دانه رازيانه (F. vulgare) } \\
\hline 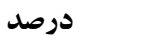 & نام تر كيب شيميايع & رديف & درصد & نام تر كيب شيميايع & 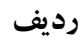 \\
\hline$\varphi /$. & (E)-2-Hexenal & 1 & $Y / V$ & \#N/A & 1 \\
\hline$\cdot / r$ & Trans-Verbenol & r & $r / 9$ & 6-Methyl-5 Heptan-2-one & r \\
\hline$\cdot / r$ & Isocornene & r & $1 / 9$ & Eugenol & r \\
\hline$\cdot / r$ & 1,7-di-epi-a-Cedrene & r & $r / r$ & Isolongifolene & f \\
\hline$\cdot / r$ & (E)- $\beta$-Farnesene & $\Delta$ & $r / V$ & 1,7-di-epi-a-Cedrene & $\Delta$ \\
\hline $19 / \Delta$ & b-Oplopenone & 4 & $r / \Delta$ & $\beta$-Carouphyllene & 9 \\
\hline$\cdot / r$ & Cubenol & $\checkmark$ & $1 / r$ & Geranyl Acetone & $\checkmark$ \\
\hline$\cdot / r$ & Oplopanone & $\wedge$ & $r / r$ & a-Zingiberene & $\wedge$ \\
\hline$\cdot / r$ & 8-a-Acetoxyelemol & 9 & $r \mu / r$ & Cadina-1,4-diene & 9 \\
\hline$\mu /$. & Isopropyl Tetradecanoate & 1. & $1 / \cdot$ & Germacrene B & 1. \\
\hline$\cdot / r$ & Flourensiadiol & 11 & $r / r$ & 10-Epi-Gamma-Eodesmol & 11 \\
\hline$\cdot / 4$ & Hexadecanol & ir & $1 / v$ & Benzyl-Benzoate & ir \\
\hline$\cdot / 1$ & Methyl Hexadecanote & ir & $1 / V$ & Flourensiadiol & ir \\
\hline$\cdot / 4$ & Methyl Hexadecanote & if & $r / \Delta$ & Heneicosane & if \\
\hline.$/ 1$ & Heneicosane & 10 & $\cdot 19$ & 1-Docosene & 10 \\
\hline & & & $r / r$ & Tricosane & 19 \\
\hline & & & $V / \Delta$ & Tetracosane & iv \\
\hline & & & $9 / 4$ & Tricosane & 11 \\
\hline
\end{tabular}


بوده است (جدول Y). تفاوت معنىدارى بين مدت زمان زمان حفاظت حفاظتدهى و اثربخشى اسانس گياهان رازيانه و دارجين

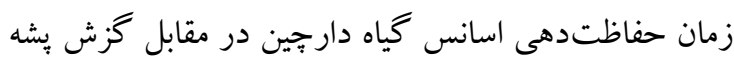
ملاحظه شد (ه •/ • (P<).

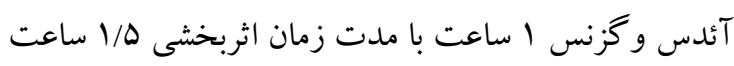
بوده است. همجنين مدتزمان حفاظتدهى براى اسانس گياه رازيانه ب ساعت با مدت زمان اثربخشى ه/ه ساعت

جدول r. مدت زمان حفاظتدهى و اثربخشى اسانسهاى دانه رازيانه و يوست دارجين روى سوزه حيوانى عليه آئدس وكز نس (Ae. vexans)

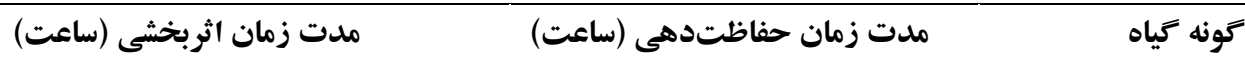

$\begin{array}{lll}1 / 0 & 1 & (\text { C. verum }) \\ r / 0 & r & (\text { F. vulgare })\end{array}$

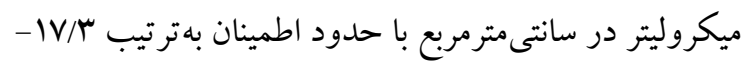
دوز مؤثر

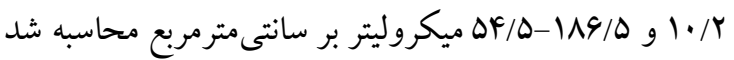
مقادير دوز مؤثر ·ه و ·9 درصد اسانس كياه دارجين 1N/| (جدول r). خط رگرسيون و معادله خطى مربوط به هر دو و و 9 9 ميكروليتر در سانتىمترمربع با حدود اطمينان به اسانس همراه با مقادير ED50 و ED90 در نمودار ب نشان ترتيب |F/F-YY/V و | داده شدهاست. سانتىمترمربع محاسبه شد (جدول ץ). همجنين مقادير دوز مؤثر •ه و •ه درصد اسانس گياه رازيانه

جدول r. تحليل ركرسيون و بر آورد دوز مؤثر اسانس دو كياه دارجين و رازيانه عليه آئدس و كزنس (Ae. vexans) روى مدل حيوانى در شرايط آزمايشكاهى

\begin{tabular}{|c|c|c|c|c|c|c|c|c|c|c|}
\hline \multicolumn{7}{|c|}{ يارامترهاى تحليل رَرسيون } & \multirow{2}{*}{ 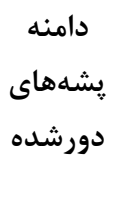 } & \multirow{2}{*}{ تشهدهاد } & \multirow{2}{*}{ (ميكروليتر د درو ديلى } & \multirow{2}{*}{ كونه تياه } \\
\hline P-Value & $\begin{array}{c}\chi^{2} \\
\text { table } \\
(d f)\end{array}$ & $\chi 2(\mathrm{H})$ & $\begin{array}{c}\text { ED }_{90} \\
\left(\mathrm{mg} / \mathrm{cm}^{2}\right) \\
\pm 95 \% \mathrm{CL}\end{array}$ & $\begin{array}{c}\text { ED50 } \\
\left(\mathrm{mg} \mathrm{cm}^{2}\right) \\
\pm 95 \% \mathrm{CL}\end{array}$ & $\mathbf{b} \pm \mathbf{S E}$ & $\mathbf{a}$ & & & & \\
\hline$\cdot 1 \cdot 1$ & $9 / Y)$ & $\cdot 1 / 99$ & $\begin{array}{l}94 / T \cdot \\
(q) / V \cdot- \\
|q \cdot / r|)\end{array}$ & $\begin{array}{l}\text { IN/IT } \\
(I F / F T- \\
\text { rT/GV) }\end{array}$ & $\begin{array}{l}1 / 1 \pm \\
\cdot / 14\end{array}$ & $-T / Y \Lambda$ & $I T-Y V$ & rt. & $G / G-\Delta r / \Lambda$ & 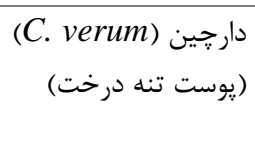 \\
\hline$\cdot 1 \cdot 1$ & $9 / \Gamma 1$ &.$/ 19$ & $\begin{array}{l}\Lambda F / Y F \\
(\Delta F / \Delta \mid- \\
\mid \wedge \varepsilon / F q)\end{array}$ & $\begin{array}{l}1 \% / 99 \\
(1 \cdot / 19- \\
1 V / 4 \Lambda)\end{array}$ & $\begin{array}{l}1 / 94 \pm \\
\cdot / \pi 9\end{array}$ & $-1 / \wedge \Delta$ & $19-\Delta$. & rT. & $G / 9-\Delta r / \Lambda$ & $\begin{array}{r}\text { (F. vulgare) } \\
\text { رازيانه) }\end{array}$ \\
\hline
\end{tabular}

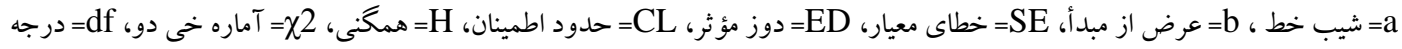




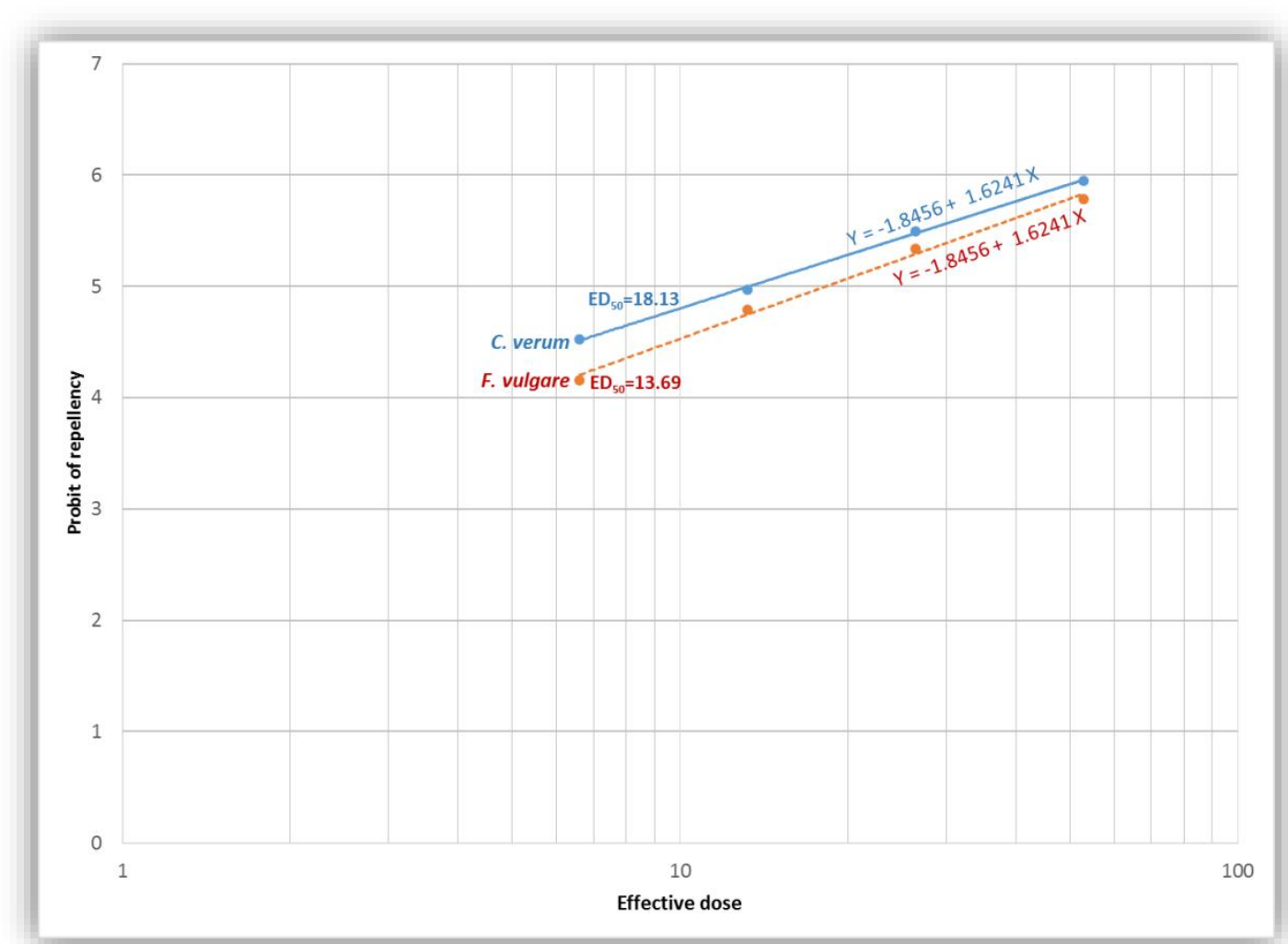

نمودار ا. بار امترهاى تحليل ركرسيون و خطوط دو دور كننده كياهى عليه آئدس وكزنس (Ae. vexans) روى مدل حيوانى

بثزوهش ديخرى اجزاء اصلى اسانس P-anisaldehyde،

و Thymol ،(-)-Fenchone ،(+)-Fenchone Estragol رازيانه گزارش شده است(Y9). در مطالعه ديخرى كاربرد عصاره متانولى دانه گياه رازيانه با اجزاء (+)-Fenchone و (z)-9-Octadecanoic acid روى يوست داوطلبين انسانى، اثرات دوركندگىى اسانس رازيانه عليه آئدس اجيبتى (Aedes aegypti) نشان داده شد(•r) و اسانس قسمت هوايى گياه رازيانه خواص لاروكشى عليه گُونه

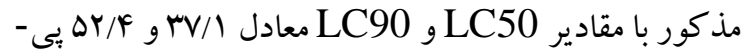
بيىام بر آورد شد(اس). آنجه قابل تأمل است تعداد تركيبات

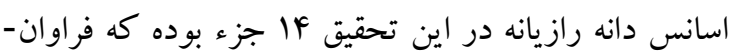
Cadina-1,4-) ترين اجزاء شيميايى كاردينا-4، الهيان

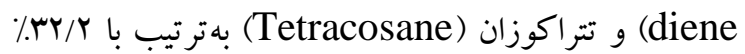

آسانترين و مؤثرترين روش جهت بيشخيرى از گزش يشهها در محيطهاى طبيعى و فضاى باز، استعمال مواد دور كننده روى يوست است و بدينترتيب ضمن محافظت از ززش، از انتقال عوامل بيمارىزاى منتقل شده از بنديايان

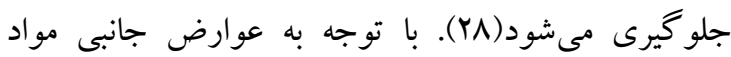

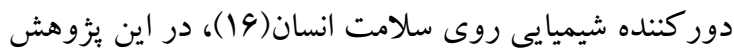

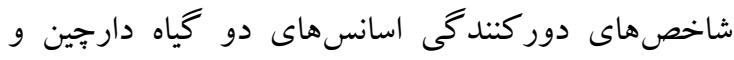

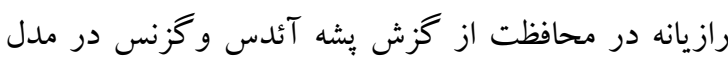
حيوانى بررسى شد كه مدت حفاظتدهى يكك و سه ساعت و دوز مؤثر 1N/1 و IT/N ميكروليتر بر سانتىترمربع بهترتيب براى اسانسهاى دارجين و رازيانه بر آورد شد. در Cadina- يُزوهش حاضر اجزاء اصلى اسانس دانه رازيانه 1,4-diene 
حاضر مطابقت دارد. خواص اسانس دارجين سيلان بهعنوان عامل كنترلى بشهها مورد ارزيابى قرار كرفته و نتايج نشان داد كه در اسانس بر گك و يوست دارجين سيلان هشت عامل كنترلى بنديايان وجود داشته و جزء اصلى اسانس در بركى

درخت دارجين سيلانى سينامالدئيد Cinnamaldehyde ) و در يوست درخت مذكور، اوزنول (Eugenol) است كه بهترتيب در غلظت س/، و و / • ميكروگرم در ميلىليتر

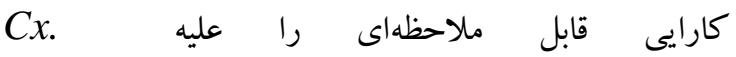
An. tessellatus و نشان داده tritaeniorhynchus است(FV). همجنين اسانس • \٪ و نانوامولسيون هـ دارجين

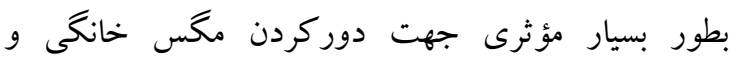
مخسهاى Haemotobia irritans روى گتاوهاى هلشتاين در فيلد به كار برده شدهاست(YV). همجنين اسانس

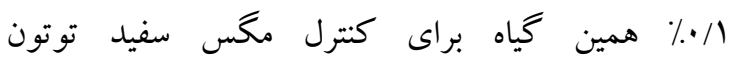
(Bemisia tabaci)

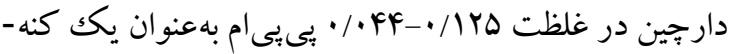

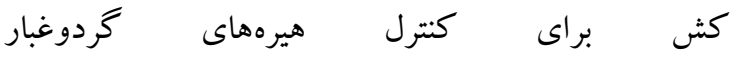
(Dermatophagoides spp.) در اسانس جدا شده با روش تقطير با آب از گونه ديخرى از درخت دارجين (Cinnamomum cassis) ها جزء شناسايى شدهاست كه تركيب اصلى اسانس ترانس-

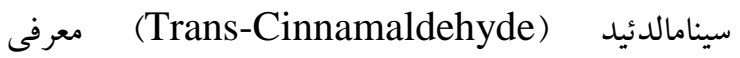
كرديدهاست و سميت تماسى و تدخينى اسانس مذكور با روش كاغذ آغشته به اسانس و محفظه بسته بهترتيب هo/V ميلى گرم در سانتىمترمربع و آ/ ميلى گرم در هوا عليه شيشه كتاب (Liposcelis bostrychophila) گزارش هُ شدهاست(19). نتايج اين يُزوهش و مقالات تطبيقى مرجع،

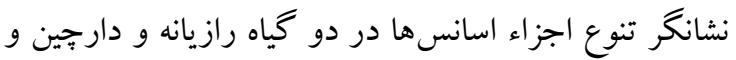

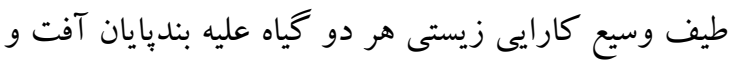
ناقلين بيمارىهاى انسانى است.
و V/D/ بوده است. در يُزوهشى در اسِانيا، اجزاء شيميايى اسانس دانه گياه رازيانه •ه تركيب شيميايى ذكر شده كه له

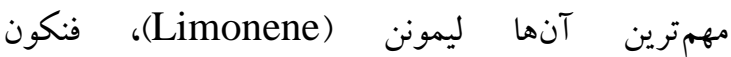
(Fenchone) تغييرات اجزاء اسانس ها به شرايط اقليمى و محل يرورش كياه نسبت داده مى شود(MF-MF)

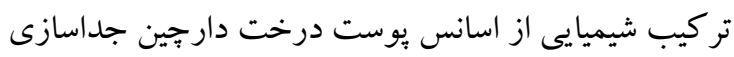

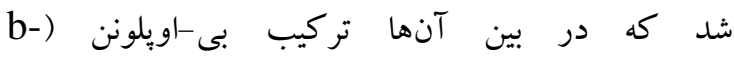

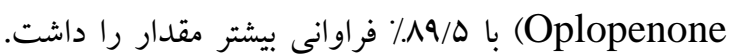
در مطالعه ديخرى، ها تركيب شامل الكلهاى اليفاتيك، الكلها، استرهاى معطر، آلدئيدهاى معطر، فنلها و و اترهاى فنوليك از اسانس دارجين جداسازى شده است(هץ). در اين يُزوهش، كاربرد اسانس •هـ٪ يوست اين درخت در

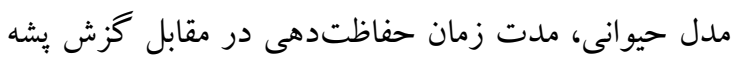

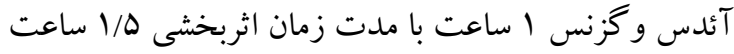

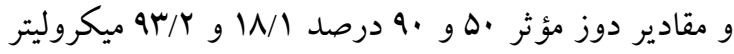
در سانتىمترمربع با حدود اطمينان بهترتيب IF/F-YY/N و  اسانس دارجين بهعنو ان دور كننده يا جهت مبارزه با بنديايان

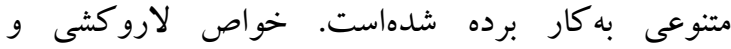
دور كندگى اسانس يوست و برگك اين درخت عليه يشههاى Anopheles , Culex tritaeniorhynchus Ae. ‘Culex quinquefasciatus ssubpictus Anopheles tessellatus و aegypti است(4)). خواص لارو كشى و دور كندگى اسانس گونه

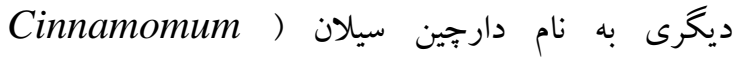
(zeylanicum عليه دو گونه يشه در كشور هند تست شده

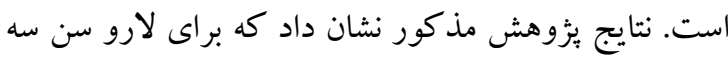

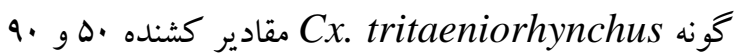

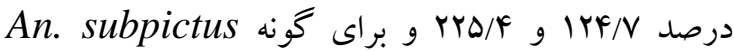

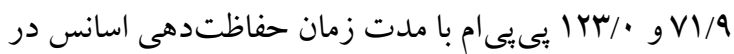
غلظت ه ميلى گرم در سانتىمترمربع براى دو گونه يشه

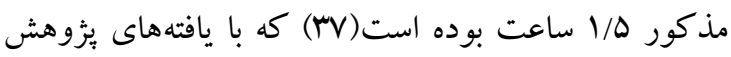




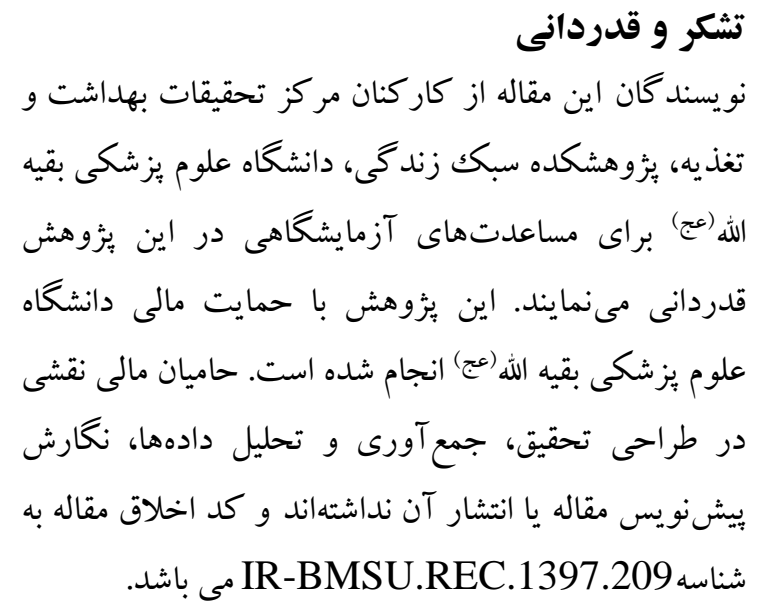

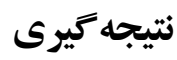

يافتهاى اين يزوهش نشان داد كه اسانس •هـ٪ دانه رازيانه با

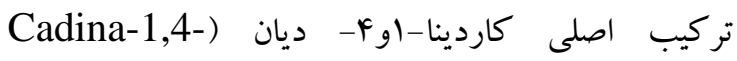
diene داراى بتانسيل قابل توجهى بهعنوان دوركنده

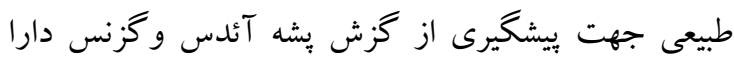
است كه در صورت استفاده علاوه بر بهرهمندى از خصيصه ترنه

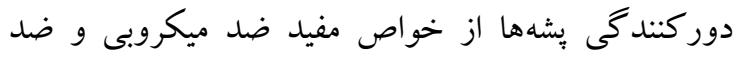

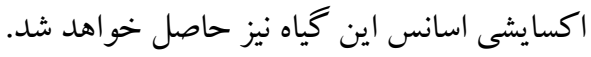

1.Azari-Hamidian S, Yaghoobi-Ershadi MR, Javadian E, Abai MR, Mobedi I, Linton YM, Harbach RE. Distribution and ecology of mosquitoes in a focus of dirofilariasis in northwestern Iran, with the first finding of filarial larvae in naturally infected local mosquitoes. Med Vet Entomol. 2009; 23(2):111-21.

2.Azari-Hamidian SH, Yaghoobi-Ershadi MR, Javadian E, Mobedi I, Abai MR. Review of Dirofilariasis in Iran. J Guilan Univ Med Sci. 2007; 15(60):102-114.

3.Mobedi I, Javadian E, Abai M. First report of focus of dog heart worm (Dirofiliria immitis) in Meshkinshahr district, northwest of Iran and its public health importance in Iran. Proceeding of First Iranian Congress of Parasitic Diseases. Guilan University of Medical Sciences, Iran, 11-13 December 1990, Rasht, Iran, p.35..

4.Sadighian A. Helminth parasites of stray dogs and jackals in Shahsavar area, Caspian region, Iran. J Helminthol. 1969; 2: 372-74.

5.Siavashi MR, Massoud J. Human cutaneous dirofilariasis in Iran: a report of two cases. Iranian J Med Sci. 1995; 20 (12): 85-6.

6.Ziyaeyan M, Behzadi MA, Leyva-Grado VH, Azizi K, Pouladfar G, Dorzaban H, et al. Widespread circulation of West Nile virus, but not Zika virus in southern Iran. PLoS Negl Trop Dis. 2018; 17(12): e0007022.

7.Chinikar S, Shah-Hosseini N, Mostafavi E, Moradi M, Khakifirouz S, Jalali T, et al. Seroprevalence of West Nile virus in Iran. Vector Borne Zoonotic Dis. 2013; 13(8):586-89.

8.Aghaie A, Aaskov J, Chinikar S, Niedrig M, Banazadeh A, Khorsand Mohammadpour H. Frequency of West Nile Virus infection in Iranian blood donors. Indian J Hematol Blood Transfus. 2016; 32(3): 343-346.

9.Meshkat Z, Chinikar S, Shakeri M, Manavifar L, Moradi M, Mirshahabi H, et. al. Prevalence of West Nile virus in Mashhad, Iran: A population-based study. Asian Pac J Trop Dis. 2015; 8(3):203-5.

10.Saidi S, Tesh R, Javadian E, Nadim A. The prevalence of human infection with West Nile in Iran. Iranian J Pub Health. 1974; 5: 8-14.

11.Mardani M, Abbasi F, Aghahasani M, Ghavam B. First Iranian imported case of dengue. Int J Prev Med. 2013; 4(9):1075-77. 
12.Heydari M, Metanat M, Rouzbeh-Far MA, Tabatabaei SM, Rakhshani M, Sepehri-Rad N, Keshtkar-Jahromi M. Dengue fever as an emerging infection in southeast Iran. Am J Trop Med Hyg. 2018; 98(5):1469-71.

13.Khoobdel M, Jafari NJ. Dengue fever: Arboviral threatening the Persian Gulf region and southern Iran. J Mil Med. 2016; 18(2):181-3.

14.O'Malley CM. Aedes vexans (Meigen): An old foe. Proc. N. J. Mosquito Control Assoc. 1990; 2(3):90-5.

15.Khoobdel M, Ahsaei SM, Farzaneh M. Insecticidal activity of polycaprolactone nanocapsules loaded with Rosmarinus officinalis essential oil in Tribolium castaneum (Herbst). Entomol Res. 2017; 47(3):175-84.

16.Koren G, Matsui D, Bailey B. DEET-based insect repellents: safety implications for children and pregnant and lactating women. Can Med Assoc J. 2003; 169(3):209-12.

17.Misni N, Nor ZM, Ahmad R. Repellent effect of microencapsulated essential oil in lotion formulation against mosquito bites. J Vector Borne Dis. 2017; 54:44-53.

18.Tavassoli M, Shayeghi M, Abai MR, Vatandoost H, Khoobdel M, Salari M, et al. Repellency effects of essential oils of myrtle (Myrtus communis), Marigold (Calendula officinalis) compared with DEET against Anopheles stephensi on human volunteers. Iran J Arthropod Borne Dis. 2011; 5(2):10-22.

19.Vatandoost H, Khazani A, Rafinejad J, Khoobdel M, Kebriaizadeh A, Abai MR. Comparative efficacy of neem and dimethyl phthalate (DMP) against malaria vector, Anopheles stephensi (Diptera: Culicidae). Asian Pac J Trop Med. 2008; 1:1-6.

20.Yaghoobi-Ershadi MR, Akhavan AA, Jahanifard E, Vatandoost H, Amin GH, Moosavi L, et al. Repellency effect of myrtle essential oil and DEET against Phlebotomus papatasi under laboratory conditions. Iran J Public Health. 2006; 35(3):7-13.

21.Bernier UR, Furman KD, Kline DL, Allan SA, Barnard DR. Comparison of contact and spatial repellency of catnip oil and $\mathrm{N}, \mathrm{N}$-diethyl-3-ethylbenzamide (DEET) against mosquitoes. J Med Entomol. 2005; 42(3):306-11.

22.Mozaffari E, Abai MR, Khanavi M, Vatandoost H, Sedaghat MM, Sanei- Dehkordi A, et al. Chemical composition, larvicidal and repellent properties of Cionura erecta (L.) Griseb against malaria vector, Anopheles stephensi Liston (Diptera: Culicidae) under laboratory conditions. Iran J Arthropod Borne Dis. 2013; 8(2):147-55.

23.Oshaghi M, Ghalandari R, Vatandoost H, Shayeghi M, Kamali-Nejad M, Tourabi- Khaledi H. Repellent effect of extracts and essential oil of Citrus limon (Rutaceae) and Melissa officinalis (Labiatae) against main malaria vector, Anopheles stephensi (Diptera: Culicidae) in Iran. Iran J Public Health. 2003; 32(4):47-52.

24.Khalaj H, Labbafi MR, Hasan Abadi T, Shaghaghi J, Hajiaghaee R. A Review on the botanical, ecological, agronomical and pharmacological properties of the fennel (Foeniculum vulgare Mill.). Med Plant J. 2017; 18(1):1-16.

25.Mahdavi S, Alizad M, Sajjadi P, Baleghi M. A study of the antioxidant and antimicrobial effects of ethanolic extract of fennel (Foeniculum vulgare Mill) seeds. J Babol Univ Med Sci. 2017; 19(5):32-8.

26.Haddi K, Faroni RA, Oliveira EE. Cinnamon oil. In: Green pesticides handbook. 2017; $118-49$.

27.Boito JP, Da Silva AS, Reis JH, Santos DS, Gebert RR, Biazus AH, et al. Insecticidal and repellent effect of cinnamon oil on flies associated with livestock. Revista MVZ Cordoba. 2018; 23(2):6628-36. 
28.Tyaghi V, Islam J, Agnihotri A, Goswami D, Rabha B, Talukdar PK, et al. Repellent efficacy of some essential oils against Aedes albopictus. J Parasitic Dis. 2016; 1(1):1-5.

29.Lee SH. Acaricidal activity of constituents identified in Foeniculum vulgare fruit oil against Dermatophagoides spp. (Acari: Pyroglyphidae). J Agric Food Chem. 2004; 52:28879.

30.Kim DH, Kim SI, Chang KS, Ahn YJ. Repellent activity of constituents identified in Foeniculum vulgare fruit against Aedes aegypti (Diptera: Culicidae). J Agric Food Chem. 2002; 50:6993-6.

31.Rocha DK, Matos O, Novo MT, Figueiredo AC, Delgado M, Moiteiro C. Larvicidal activity against Aedes aegypti of Foeniculum vulgare essential oils from Portugal and Cape Verde. Nat Prod Commun. 2015; 10(4):677-82.

32.Paranagama PA, Wimalasena S, Jayatilake GS, Jayawardena AL, Senanayake UM, Mubarak AM. Comparison of essential oil constituents of bark, leaf, root and fruit of Cinnamon grown in Srilanka. J Natl Sci Found. 2001; 29 (3-4):147-53.

33.Pirmohammadi M, Shayeghi M, Vatandoost H, Abai MR, Mohammadi A, Bagheri A, et al. Chemical composition and repellent activity of Achillea vermiculata and Satureja hortensis against Anopheles stephensi. Iran. J Arthropod Borne Dis. 2016; 10(2):201-10.

34.Moghaddam M, Farhadi N. Influence of environmental and genetic factors on resin yield, essential oil content and chemical composition of Ferula asafoetida L. populations. J Appl Res Med Arom Plant. 2015; 2(3):69-76.

35.Rajeswara Rao BR, Rajput DK, Bhattacharya AK. Essential oil composition of petiole of Cinnamomum verum Bercht \& Pres. J Spices Aromat Crops. 2007; 16(1):38-41.

36.Govindarajan M. Larvicidal and repellent properties of some essential oils against Culex tritaeniorhynchus Giles and Anopheles subpictus Grassi (Diptera: Culicidae). Asian Pac J Trop Med. 2011; 4(2):106-11.

37.Samarasekera R, Kalhari KS, Weerasinghe IS. Mosquitocidal activity of leaf and bark essential oils of Ceylon Cinnamomum zeylanicum. J Essent Oil Res. 2005; 17(2):301-3.

38.Deletre E, Chandre F, Barkman B, Menut C, Martin T. Naturally occurring bioactive compounds from four repellent essential oils against Bemisia tabaci whiteflies. Pest Manag Sci. 2016; 72(1):179-89.

39.Liu XC, Cheng J, Zhao NN, Liu ZL. Insecticidal activity of essential oil of Cinnamomum cassia and its main constituent, trans-cinnamaldehyde, against the booklice, Liposcelis bostrychophila. Trop J Pharm Res. 2014; 13(10):1697-702. 